\title{
Assessment of the Wind and Wave Climate of the Hellenic Seas Using 10-Year Hindcast Results
}

\author{
Takvor Soukissian", Aristides Prospathopoulos, Maria Hatzinaki and Maria Kabouridou
}

\author{
Hellenic Centre for Marine Research, Institute of Oceanography, Anavyssos, Greece
}

\begin{abstract}
In this work, the wind and wave climate of the Hellenic Seas, based on 10-year hindcast data, is described in detail. The wind and wave hindcast was carried out using an improved version of the SKIRON-Eta atmospheric model and the WAM-cycle 4 wave model with a high spatial resolution of $0.1^{\circ} \times 0.1^{\circ}$ and a model time step of 3 hours, in order to resolve efficiently offshore wind and wave conditions. The results cover the period 1995-2004 and are presented in the form of charts of the spatial distribution of specific wind and wave parameters as well as frequency histograms, on a seasonal and annual basis. The hindcast data were calibrated by means of measured wind and wave data from the POSEIDON buoy network. Based on the calibrated hindcast results, a description of the main characteristics of the wind and wave climate of the Hellenic Seas is being attempted, while the corresponding dominant features are revealed and represented as precisely as possible.
\end{abstract}

\section{INTRODUCTION}

Availability of long-term wind and wave data in offshore and coastal areas is important to a number of marine applications and operations, such as the design and construction of offshore and coastal structures, the management and protection of coastal environment, tourist and land-planning development of coastal areas and islands, vulnerability and risk analysis of inhabited coastal areas, as well as the feasibility analysis for wind and wave energy utilization in specific sea areas. In addition, long-term records of wind and wave parameters, such as wind speed and direction, significant wave height, wave period and wave direction, provide a solid ground for climate analysis on local, regional and global scales. Wind and wave climate analysis deals mainly with the long-term statistical behaviour of these parameters as well as with their variability in space and time. An effective way to retrieve the relevant long-term information is wind and wave hindcasting. This work presents a 10 -year wind and wave hindcast data analysis for the Hellenic Seas in order to assess and model the corresponding climate.

Wind and wave long-term data of an extended geographical area are usually summarized in the form of a wave and wind Atlas. The majority of Atlases that have been produced for various parts of the globe include mostly hindcast data or data from visual observations. So far, the sole uniquely Hellenic effort for assessing and describing the climate of the Hellenic Seas was the "Wind and Wave Atlas of Northeastern Mediterranean Sea", Athanassoulis, Skarsoulis [1], which was based on visual observations for the Northeastern Mediterranean Sea, accumulated during 18501980 from the Met Office, England, and presented on a grid with dimensions $1^{\circ} \times 1^{\circ}$. A recent wind and wave Atlas for the Mediterranean Sea, [2], completed in 2004, was based on hindcast results obtained from the WAM-Cycle 4 wave

*Address correspondence to this author at the Hellenic Centre for Marine Research, Institute of Oceanography, Anavyssos, Greece;

E-mail: tsouki@ath.hcmr.gr model, with a spatial resolution of $0.25^{\circ}\left({ }^{1}\right)$. Such a resolution, while appropriate for a general description of the wind and wave climate of the entire Mediterranean, is insufficient for areas characterized by significant local complexities. For example, Aegean Sea is a semi-closed basin with complex bathymetry and abrupt changes, in addition to many insular groups. The use of hindcast data produced by numerical models of high spatial and temporal resolution is the only way to represent as precisely and accurately as possible the main characteristic features of the wind and wave climate of the Hellenic Seas. Such numerical models have been implemented and applied previously to produce 10-year hindcast data, presented in the very recent "Wave and Wind Atlas of the Hellenic Seas", see Soukissian et al. [4]. In the same work, measured data was also systematically presented for the Hellenic Seas. In the current study, characteristic hindcast results from the above Atlas are presented, while the main original contribution is the extraction and description of annual and seasonal wind and wave climatic features for the Hellenic Seas.

The results of this work refer to the region defined by the coordinates (see Fig. 1).

$$
\left(42.25^{\circ} \mathrm{N}, 19.00^{\circ} \mathrm{E}\right),\left(42.25^{\circ} \mathrm{N}, 30.00^{\circ} \mathrm{E}\right) \text {, }
$$$$
\left(30.25^{\circ} \mathrm{N}, 19.00^{\circ} \mathrm{E}\right),\left(30.25^{\circ} \mathrm{N}, 30.00^{\circ} \mathrm{E}\right) \text {. }
$$

The wind and wave hindcast data for the examined 10-year period (1995-2004) have been generated by a non-hydrostatic weather model (an improved version of the SKIRON-Eta model) and a $3^{\text {rd }}$ generation wave model (WAM-cycle 4 model), using a spatial resolution of $0.1^{\circ} \times 0.1^{\circ}$ and a temporal resolution of three hours. The results of the models (wind speed $U_{W}$, significant wave height $H_{S}$ and spectral peak period $T_{P}$ ) were calibrated (corrected) with collocated in-situ measurements referring to the joint time window 1999-2004.

(1) Another Atlas for the Baltic, North, Black, Azov and Mediterranean seas, based on nested wave models (Wave Watch and SWAN), has been published by the Russian Maritime Register of Shipping (2006), [3]. 
The wind and wave measurements were collected from six (6) oceanographic buoys of the POSEIDON network, see Soukissian et al. [5], and used after an appropriate filtering process. The use of satellite data was avoided, due to the sparse spatial and temporal coverage of the Hellenic Seas from TOPEX/Poseidon and JASON; in addition, the reliability of the satellite data as far as the Aegean Sea is considered, has been described as inadequate, [6]; see also below.

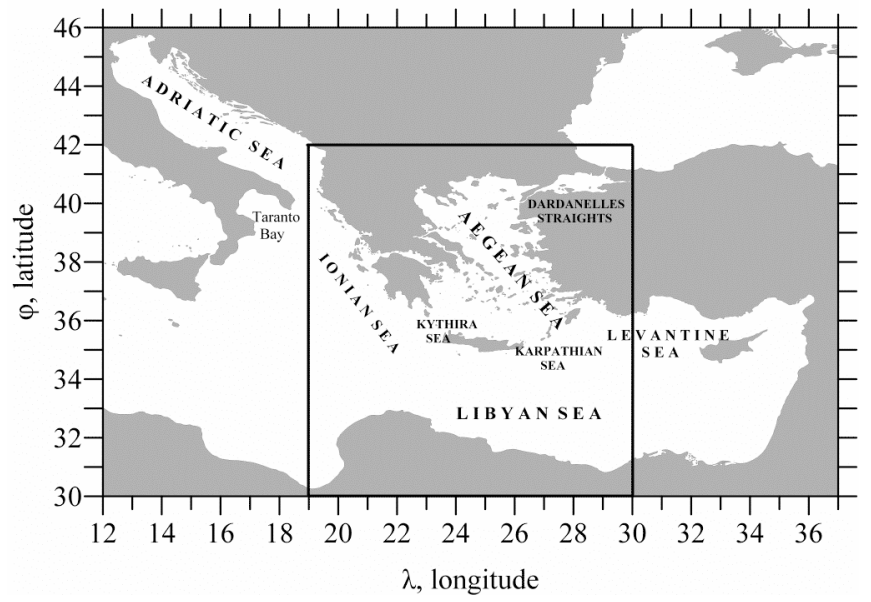

Fig. (1). The area under study (enclosed within the box).

The following section describes briefly the numerical models used for the generation of wind and wave hindcast data, the calibration of the model results and the wind and wave measurement process. Characteristic seasonal spatial distribution charts of wind and wave parameters, as well as isopleths corresponding to threshold exceedance events, are also presented for the entire study area. In addition, frequency histograms of wind and wave hindcast data and polar diagrams are included for the location where the most extreme mean annual wave conditions were observed. Finally, an assessment of the annual and seasonal wind and wave climate of the Hellenic Seas, based on the 10-year hindcast time series, is attempted and the conclusions of the work are presented.

\section{MATERIAL AND METHODS}

\section{Hindcast Data}

\section{The Weather Model}

The weather model used in this work was based on an improved version of the non-hydrostatic model SKIRONEta, Messinger et al. [7], Kallos et al. [8], Papadopoulos et $a l$. [9]. The model was integrated over an area covering a large part of Europe and North Africa (see Fig. 2).

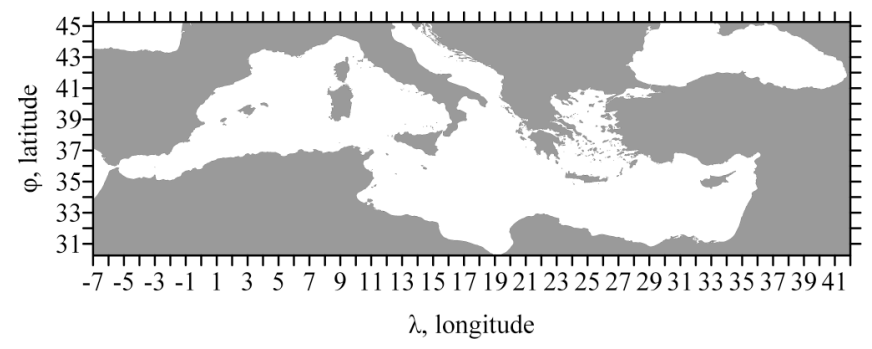

Fig. (2). The geographical area of the weather and wave model implementation.
The spatial resolution of the model was set to $0.1^{\circ} \times 0.1^{\circ}$ (about 9x11 km) and the time step of the numerical integration to $36 \mathrm{sec}$. Vertically 38 levels are used, stretching from the bottom to top, with layer depths that range from $20 \mathrm{~m}$ in the planetary boundary layer to $2 \mathrm{~km}$ at $50 \mathrm{mb}$. More specifically, although the Eta coordinate system is pressure-based and normalized, the height of each vertical level can be defined at 19.5, 61.7, 112.2, 181.1, 269.8, 378.3, 506.7, 654.8, $822.6,1010.4,1218.1,1446.1,1694.6,1964.2,2255.1$, $2568.1,2903.9,3263.3,3647.3,4057.0,4493.8,4959.1$, 5455.0, 5983.4, 6547.1, 7148.2, 7786.2, 8452.9, 9129.6, $9799.3,10469.8,11185.0,12006.2,12983.1,14151.6$, $15566.1,17232.5$ and $19321.7 \mathrm{~m}$. The meteorological input used for defining the initial and boundary conditions of the model were obtained from the analysis fields, produced at European Center for Medium-Range Weather Forecasts (ECMWF). Input has been available at a $0.5^{\circ} \times 0.5^{\circ}$ resolution and 16 standard pressure levels $(1000,925,850,700,500$, $400,300,250,200,150,100,70,50,30,20$ and $10 \mathrm{hPa})$ every 6 hours (at 00, 06, 12 and 18 UTC). Information concerning the ground temperature and humidity at 4 ground layers (defined at the depths of $7 \mathrm{~cm}, 28 \mathrm{~cm}, 100 \mathrm{~cm}$ and $255 \mathrm{~cm}$ ), as well as the temperature of the sea surface, were derived from ECMWF at a $0.5^{\circ} \times 0.5^{\circ}$ resolution.

Corresponding analysis fields produced during the operational use of ECMWF and obtained through MARSMeteorological Archive and Retrieval System have also been used. The Hellenic National Meteorological Service (HNMS) was responsible for the collection of necessary data concerning the decade 1995-2004. The Hellenic Centre for Marine Research (HCMR) was in charge of the hindcast runs. The hindcast wind field (speed and direction at $10 \mathrm{~m}$ over the sea surface) was used as the atmospheric forcing for the wave model and was further analyzed in order to produce wind hindcast data.

\section{The Wave Model}

The wave model used in this work was based on the $3^{\text {rd }}$ generation model WAM-Cycle 4, WAMDI Group [10], Komen et al. [11]. The WAM-Cycle 4 (WAM hereafter) calculates the spatial-temporal evolution of the wave spectrum, taking into account wave generation due to the wind forcing, wave refraction due to change of bathymetry and presence of currents, transformation of energy due to non-linear quadruplet wave interactions and energy absorption due to white capping and bottom friction. The model was modified in order to be effective for applications of high spatial resolution, concerning both accuracy and computing power aspects.

The application area of the model was extended from $7^{\circ} \mathrm{W}$ to $42^{\circ} \mathrm{E}$ and $30.25^{\circ} \mathrm{N}$ to $45.25^{\circ} \mathrm{N}$ (see also Fig. 2 ) and the spatial resolution was set to $0.1^{\circ} \times 0.1^{\circ}$. The particular geographical coverage has been considered adequate for the proper simulation of the development and propagation of waves in the two basins (Mediterranean and Black Sea). The bathymetry was adapted to the spatial resolution of the model grid through bilinear interpolation of the worldwide 
bathymetry/topography ETOPO $2\left({ }^{2}\right)$ with spatial resolution of $2^{\prime}$ ( $1^{\prime}$ equals $1852 \mathrm{~m}$ at the equator) and vertical accuracy of $1 \mathrm{~m}$. In the cases of deficiency of the above database (in shallow water areas of the two basins), corrections based on nautical charts of the Hellenic Navy Hydrographical Service were introduced. The spectral frequency resolution of the model was determined by a logarithmic distribution, namely $f_{i+1}=1.1 f_{i}$, where the minimum frequency was set to $0.05 \mathrm{~Hz}$ and the maximum frequency to $0.793 \mathrm{~Hz}$ (30 frequency sectors in total). The directional resolution was set to $15^{\circ}$, resulting in 24 directional sectors.

Significant wave height $\left(H_{S}\right)$, mean wave period and mean wave direction $\left(\theta_{\text {WAVE }}\right)$ were obtained as integrated products of the wave spectrum, while spectral peak period $\left(T_{P}\right)$ and wave energy corresponding to the low-frequency and the high-frequency part of the spectrum were derived from the distribution of the spectrum.

It is worth noting that both weather and wave models had the same spatial resolution $\left(0.1^{\circ} \times 0.1^{\circ}\right)$ and nearly the same land-sea masks, thus avoiding multiple linear interpolations for the calculation of wind parameters at the grid points of the wave model.

\section{Calibration (Correction) of WAM Model Results}

In general, WAM model underestimates the high values of the significant wave height and the spectral peak period; see e.g. Soukissian et al. [12], Soukissian, Prospathopoulos [13], Med-Atlas Group [2], Sterl, Caires [14]. A part of this error could be attributed to a corresponding deviation of the weather model output from the real values of the wind speed.

In the case of large geographical areas, where an efficient number of measurement data points (from satellite or other measuring devices) are available, hindcast results can be calibrated using the following procedure, see e.g. $[2,6]$ :

1) Selection of the calibration locations where measurements are available

2) Collocation of hindcast data and measurements

3) Implementation of a linear regression method and estimation of the local regression coefficients

4) Extrapolation of the local regression coefficients to the entire examined area and derivation of the corresponding contours of the constant regression coefficients.

The above method was not used in this work, since:

- $\quad$ the study area was very small,

- $\quad$ the spatial and temporal coverage of the Hellenic Seas from TOPEX/Poseidon and its successor JASON is very sparse,

- $\quad$ as far as the Aegean and adjacent seas are concerned, the available satellite data are of questionable reliabil-

${ }^{2}$ ) U.S. Department of Commerce, National Oceanic and Atmospheric Administration, National Geophysical Data Centre, 2006. 2-minute Gridded Global Relief Data. ity, because of the presence of multiple island clusters creating "noise" in satellite measurements, and

- the reference points along the satellite tracks corresponded only to offshore locations and could result in a biased calibration procedure.

Due the above reasons, the use of satellite data would led to significant statistical uncertainties. Thus, the calibration/correction of the model results was based on the buoy measurements at the locations M1-M6 (see Table 1 and Fig. 3). "Mean" correction relationships were obtained and the model results were improved uniformly, i.e., throughout the entire study area. It should be noted here, that the buoy locations were scattered all over the Aegean Sea and the corresponding measurements had adequate sample sizes with respect to the period of study.

The classical calibration (correction) problem can be described as follows: Supposedly an accurate instrument is available and is considered as the reference measuring device (in our case the wave buoy measurements). In addition a less accurate instrument, whose measurements are fairly correlated with the reference measurements (in our case the collocated WAM wave model data), is also available.

Table 1. Information About the Locations from which Measured Data are Used in the Calibration Procedure

\begin{tabular}{|c|c|c|c|}
\hline Station Name (ID) & Location & Meas. Period & Depth (m) \\
\hline \hline Athos (M1) & $40.0^{\circ}-24.7^{\circ}$ & 19992004 & 220 \\
\hline Lesvos (M2) & $39.1^{\circ}-25.8^{\circ}$ & $1999-2004$ & 131 \\
\hline Egina (M3) & $37.8^{\circ}-23.5^{\circ}$ & $1999-2004$ & 90 \\
\hline Mykonos (M4) & $37.5^{\circ}-25.5^{\circ}$ & $1999-2004$ & 140 \\
\hline Santorini (M5) & $36.2^{\circ}-25.5^{\circ}$ & $1999-2004$ & 320 \\
\hline Avgo (M6) & $35.6^{\circ}-25.6^{\circ}$ & $2000-2004$ & 360 \\
\hline
\end{tabular}

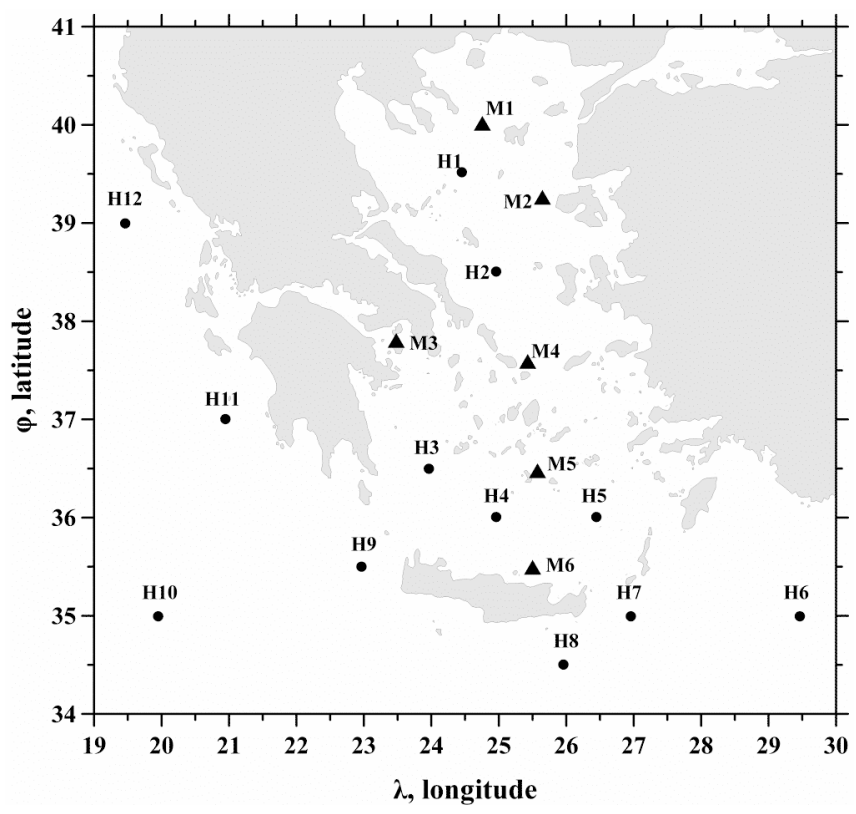

Fig. (3). The locations for which detailed hindcast results $(\bullet)$ and measured data $(\boldsymbol{\Delta})$ are available. 
Denoting the measurement of the reference instrument as $X$ and the measurements of the less accurate instrument as $Y$, the calibration problem is to find means to "correct" the measurements $Y$ of the less accurate instrument in order to be as close as possible to the measurements $X$ of the reference device. One of the most frequently used statistical methods to deal with the above problem is linear regression: the dependent variable $Y$, measured with an error, is regressed on the error-free variable $X$ and the obtained result (regression function) is used to estimate the $x_{0}$ value of an unknown sample from its measured value $y_{0}$. Regressing $Y$ on $X$ (i.e., regressing the model values to the collocated measurements), the regression parameter estimates $b_{0}$ and $b_{1}$ are obtained and the regression equation is established:

$y_{i}=b_{0}+b_{1} x_{i}, \quad i=1,2, \ldots, n$.

Rearranging this equation with respect to $x$ we obtain

$x_{i}=\frac{y_{i}-b_{0}}{b_{1}}, \quad i=1,2, \ldots, n$.

In our case regression through the origin was applied, implying that the general regression relationship is of the form

$y_{i}=b x_{i}, \quad i=1,2, \ldots, n$,

and thus the calibration (correction) relation becomes

$x_{i}=\frac{y_{i}}{b}, \quad i=1,2, \ldots, n$

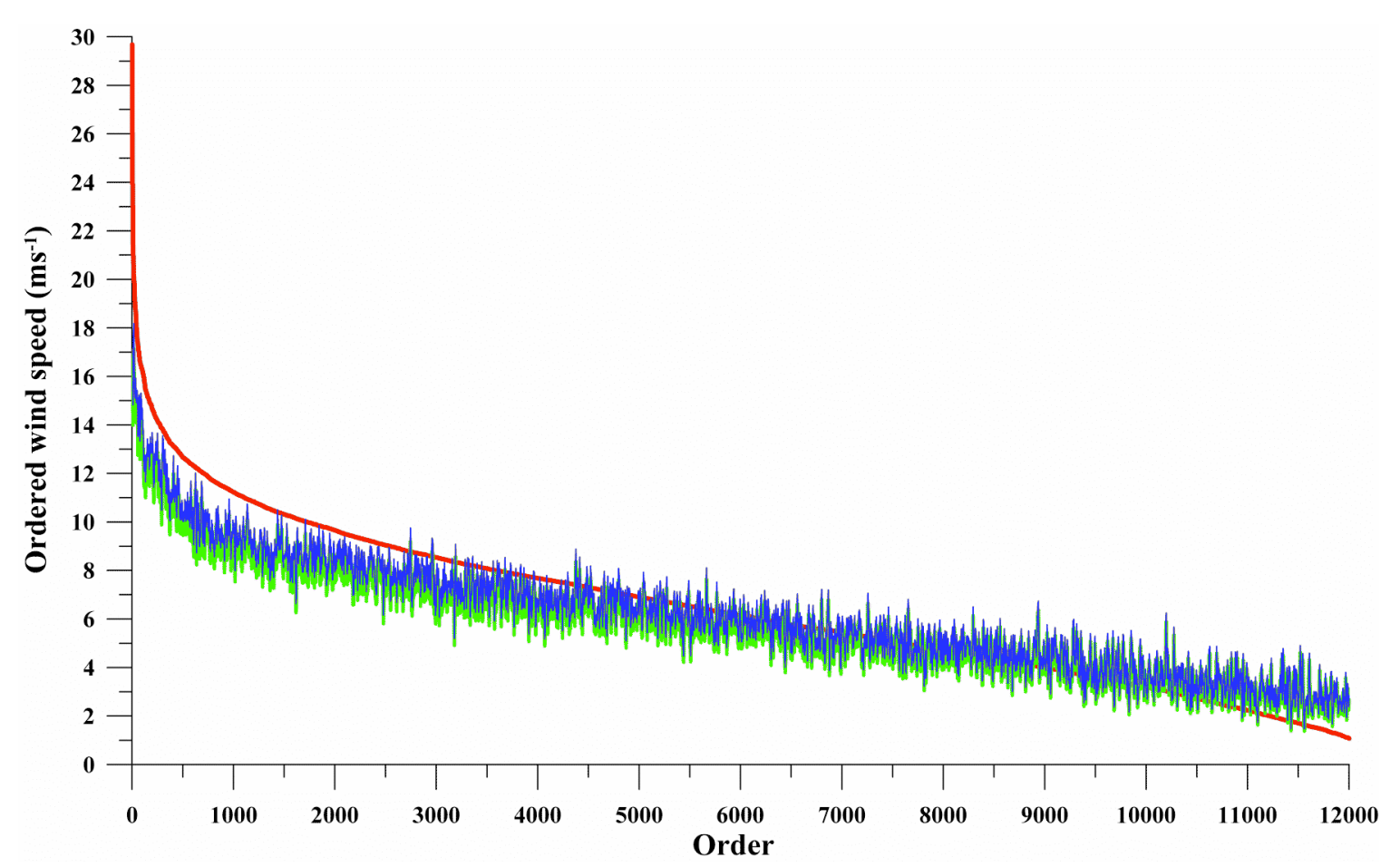

Fig. (4). Time series plot of measured $U_{W}$ (red curve) and 10-point moving averaged time series of hindcast $U_{W}$ for location M2, before (green line) and after (blue line) the calibration procedure. where $x$ is the corrected value of the WAM wave model and $y$ is the initial value of the model output. An original calibration procedure for the results of the WAM wave model in the North Aegean Sea is presented in detail in Soukissian, Prospathopoulos [15]. The same method was applied for calibrating locally satellite wave measurements of TOPEX/Poseidon, Soukissian, Kehris [16].

In this work, both classical linear regression and quantilequantile (q-q) linear regression (proposed among others by Wang, Swail [17]) were examined for the production of the correction relationships for significant wave height and wind speed. The correction for the spectral peak period was based on the corresponding correction for significant wave height, Eurowaves Group [6]. The classic linear regression gave slightly better results than the $\mathrm{q}-\mathrm{q}$ regression. The final relationships used for the correction of the hindcast significant wave height, spectral peak period and wind speed are presented below

$$
\begin{aligned}
& H_{S, W A M}=1.15 H_{S, W A M}, \\
& \mathbb{T}_{P, W A M}=1.07 T_{P, W A M}, \\
& \mathcal{U}_{W, W A M}=1.06 U_{W, W A M},
\end{aligned}
$$

where the $X^{4}$ variables denote the corrected values of numerical models and the $X$ variables denote the initial ones.

The time series of measured wind speed $\left(U_{W}\right)$ and significant wave height $\left(H_{S}\right)$ for location M2 are plotted in Figs. (4) and (5) respectively, in decreasing order of magnitude, together with the time series of the corresponding hind- 


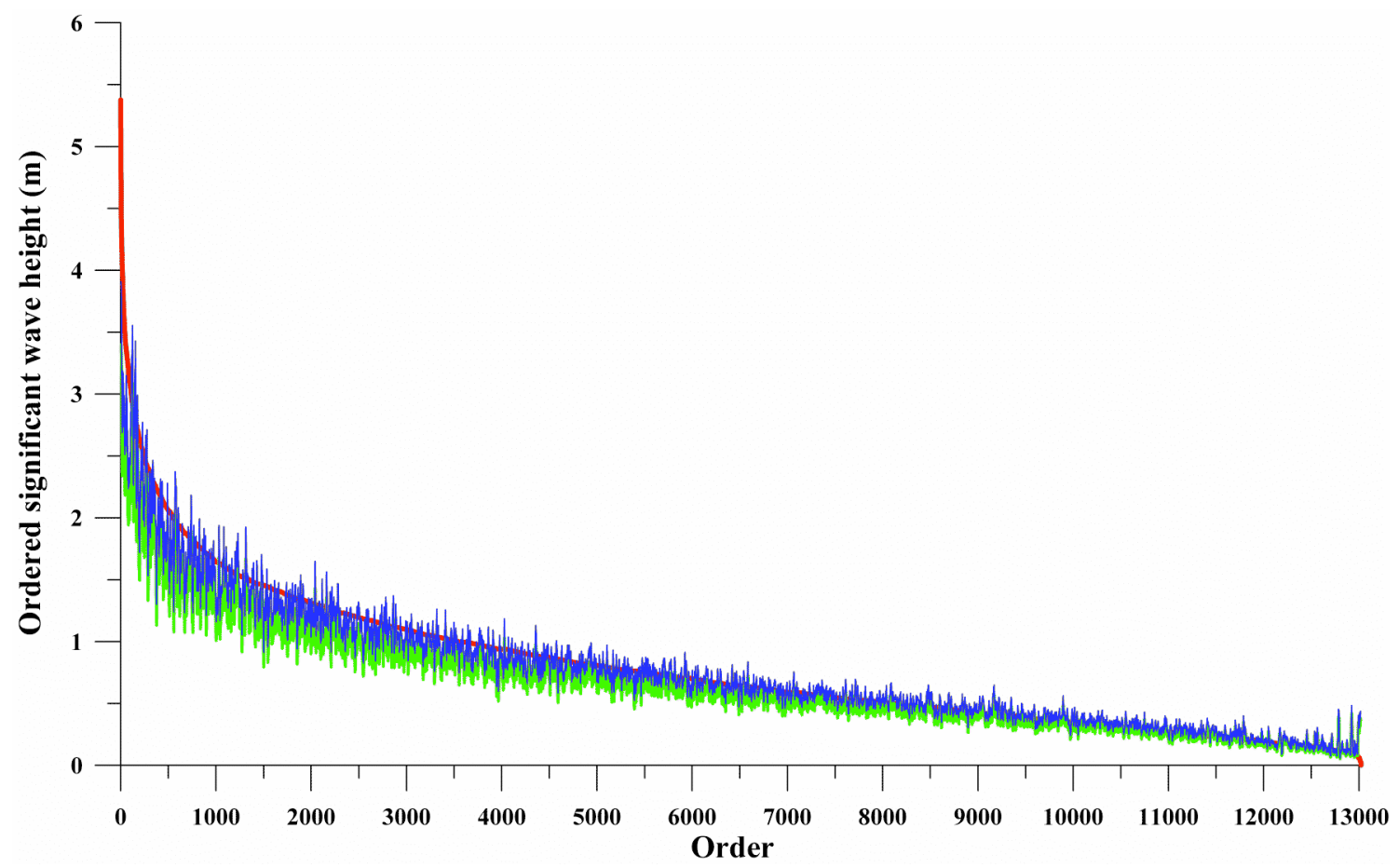

Fig. (5). Time series plot of measured $H_{S}$ (red curve) and 10-point moving averaged time series of hindcast $H_{S}$ for location M2, before (green line) and after (blue line) the calibration procedure.

cast parameters as obtained before and after the calibration. The hindcast time series were smoothed by applying a 10point moving average to allow an easy distinction and without losing essential information of their behaviour. It is observed that the calibration procedure improved the results of the numerical models in the segments between moderate and high values of the examined parameters, which are of significant importance.

Equations (3)-(5) are representative of the Hellenic Seas for the time period studied and the specific adjustments of the numerical models. In this context, their accuracy may not be high if applied to a specific area; in any case, they should not be used for correction of forecasting results. Relations (3)-(5) verify that the general trend of WAM model as concerns the Hellenic Seas is the same with that observed in other works, e.g., $[12,13]$, namely systematic underestimation of practically all spectral parameters.

\section{Wind and Wave Measurements}

The wind and wave measurements used for the calibration of the model results are referred to six (6) locations of the Hellenic Seas; see Table 1 and Fig. (3). The selection criterion for those locations was mainly the statistical adequacy and the sufficiency of the sample size of the measurements, although problems relative to the instrumentation - especially the first couple of years of the POSEIDON System operation - led to the discard of some measured values as erroneous.

The measurements were taken every 3 hours with recording period $1020 \mathrm{~s}$ for wave and $600 \mathrm{~s}$ for wind measurements. Both the wave recorder (accelerometer) and the anemometer have a sampling period of $1 \mathrm{~Hz}$.
Spectral wave parameters are calculated by means of spectral moments. The $\mathrm{n}$-th order spectral moment is defined as:

$m_{n}=\int_{\omega_{0}}^{\omega_{1}} S_{\eta \eta}(\omega) d \omega, n=\ldots,-1,0,2, \ldots$

where $S_{\eta \eta}(\omega)$ is the sea-surface elevation spectrum. The limit frequencies for the spectrum are $\omega_{0}=0.04 \mathrm{~Hz}$ and $\omega_{1}=0.50 \mathrm{~Hz}$, providing spectral estimates with 32 degrees of freedom. The most important wave spectral parameters are calculated as follows:

- $\quad$ Significant wave height $H_{S}$ (in $\mathrm{m}$ ):

$H_{S} \approx 4 \sqrt{m_{0}}$,

where $m_{0}$, is the zero-th order spectral moment.

- Mean wave direction $\theta_{\text {WAVE }}$ (in deg):

$\theta_{W A V E}=\arctan \left(\frac{b}{a}\right)$,

where

$a=\frac{\int_{\omega_{0}}^{\omega_{1}} S_{\eta \eta}(\omega) \cos \varphi(\omega) d \omega}{m_{0}}$,

$b=\frac{\int_{\omega_{0}}^{\omega_{1}} S_{\eta \eta}(\omega) \sin \varphi(\omega) d \omega}{m_{0}}$, 
and $\varphi(\omega)$ is the (frequency dependent) wave direction. $\theta_{\text {WAVE }}$ indicates the direction from which waves (sea states) propagate. The limit frequencies $\omega_{0}$ and $\omega_{1}$ in equations (9a) and (9b) are $\omega_{0}=0.04 \mathrm{~Hz}$ and $\omega_{1}=0.50 \mathrm{~Hz}$.

- $\quad$ Spectral peak period $T_{P}$ (in s), i.e., the wave period corresponding to the spectral peak $\omega_{P}$ :

$T_{P}=\frac{2 \pi}{\omega_{P}}$

It should be noted that:

- $\quad$ Some values of the spectral peak period $T_{P}$ were found to be smaller than $2 \mathrm{~s}$ and discarded, since they are close to the sampling frequency of the buoy.

- $\quad$ The wind speed $U_{W}$ used in the calibration procedure is the mean value of the wind measurements (taken during the recording period of $600 \mathrm{~s}$ ). All values $U_{W}<0.05 \mathrm{~ms}^{-1}$ were discarded, since they are very close to the operation limits of the anemometer. The wind direction $\theta_{W I N D}$ indicates the direction from which wind blows.

\section{RESULTS AND DISCUSSION}

The results obtained from the 10-year hindcast analysis can be presented in a variety of ways, see Soukissian et al. [4]:

(i) Charts of spatial distribution of wind and wave parameters in a seasonal and annual basis.

(ii) Bivariate histograms of frequency of occurrence of wind and wave parameters in a seasonal and annual basis $\left({ }^{3}\right)$.

(iii) Due to the large amount of figures and charts that could potentially be presented here, only some representative charts and histograms have been chosen to be included in this work.

Charts illustrating the spatial distributions of mean wind speed, wind directionality, mean significant wave height and wave directionality are presented in Figs. (6-9), respectively, referring to the winter period.

The spatial distribution of wave height and wind speed is represented by contours of constant mean values (isolines). The spatial distribution of wind and wave directionality is represented by the three most probable directions (among 24 equally spaced directions considered) at selected grid points of the studied area. Arrows show the direction from which wind blows or waves propagate. The arrow length corresponds to the frequency of occurrence (\%) of wind blow or wave propagation from the corresponding direction. The

$\left(^{3}\right)$ In [4], the following results are presented: a) Contours of wind and wave parameters and isopleths for different threshold values, spatial distribution of the most probable wind and wave directions, etc, and b) seasonal and annual bivariate histograms of hindcast wind and wave parameters for twelve (12) characteristic grid points of the Hellenic Seas; see also Fig. 3. length of the reference arrow is 30 , i.e. it corresponds to frequency of occurrence $30 \%$. Only wind speeds greater than $6 \mathrm{~ms}^{-1}$ and significant wave heights greater than $1 \mathrm{~m}$ have been considered.

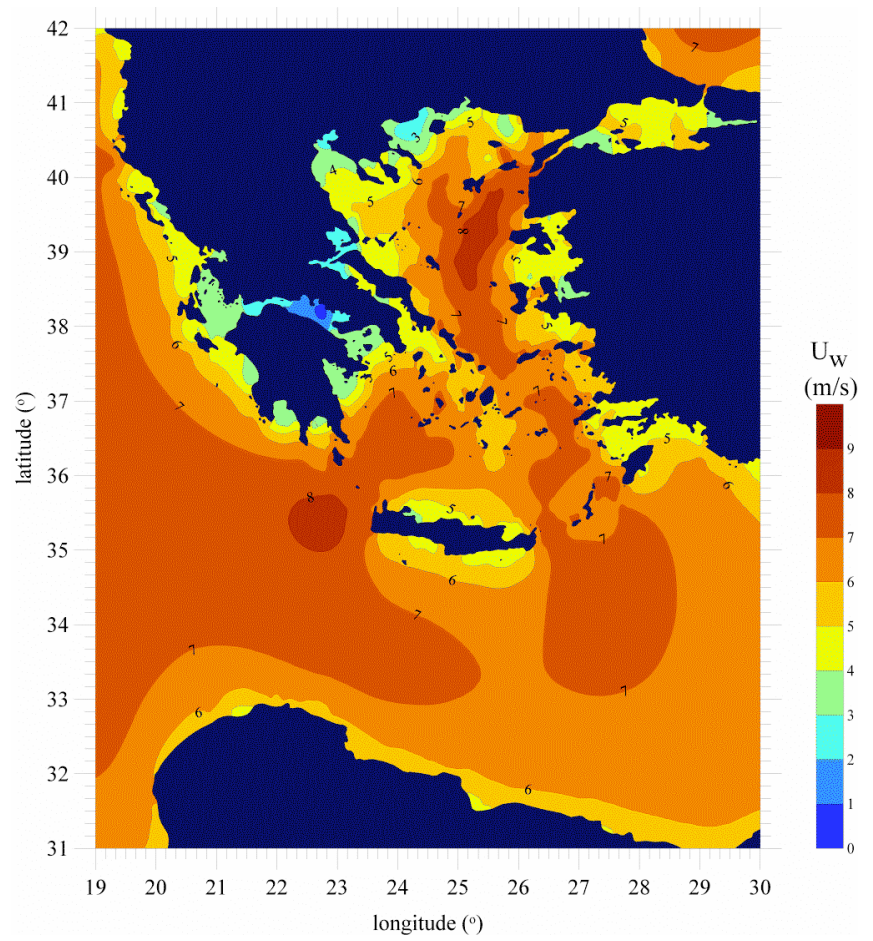

Fig. (6). Spatial distribution of mean wind speed for winter in the studied area.

Regions of intense wind and sea states in the Hellenic Seas can be observed for the winter period in Figs. $(\mathbf{6 , 8})$. More specifically, areas of the highest mean values of wind speed during winter characterize

(i) the lengthwise zone extended from north-central to central Aegean and

(ii) the circular zone southwest of the straits between Kythira Isl. $\left(^{4}\right)$ and Crete Isl. (see contours of $8 \mathrm{~m} / \mathrm{s}$ (Fig. 6)).

The most probable wind directions in the Aegean Sea are those aligned within the arc extending from north (Dardanelles straits) to south (straits between Crete Isl. and Rhodes Isl.); see also Axis A in Fig. (16). In the Ionian Sea the wind directions were rather scattered and there was a lack of a definite dominant direction. In the Libyan Sea W-NW to ESE directions were rather dominant with much smaller frequencies of occurrence than the ones found in the Aegean Sea.

Similar patterns can be observed in the spatial behaviour of the significant wave height. The areas of the highest mean values of significant wave height were found to be

(i) the zone southwest of the straits between Kythira Isl. and Crete Isl. and

$\left(^{4}\right)$ All the toponyms mentioned in the text are shown in Fig. (16). 
(ii) the zone southeast of the straits between Crete Isl. and Kassos Isl. (see contours of $1.7 \mathrm{~m}$ and $1.6 \mathrm{~m}$, respectively (Fig. 8)).

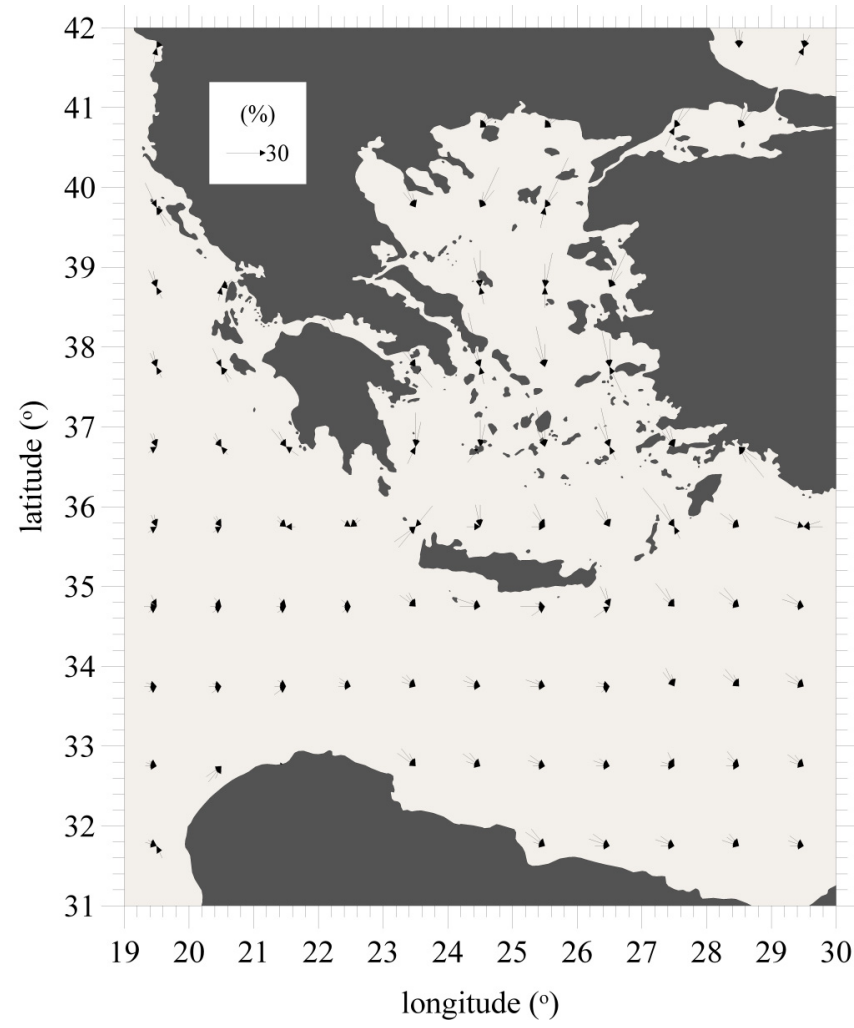

Fig. (7). Spatial distribution of the three most probable wind directions for winter in the studied area.

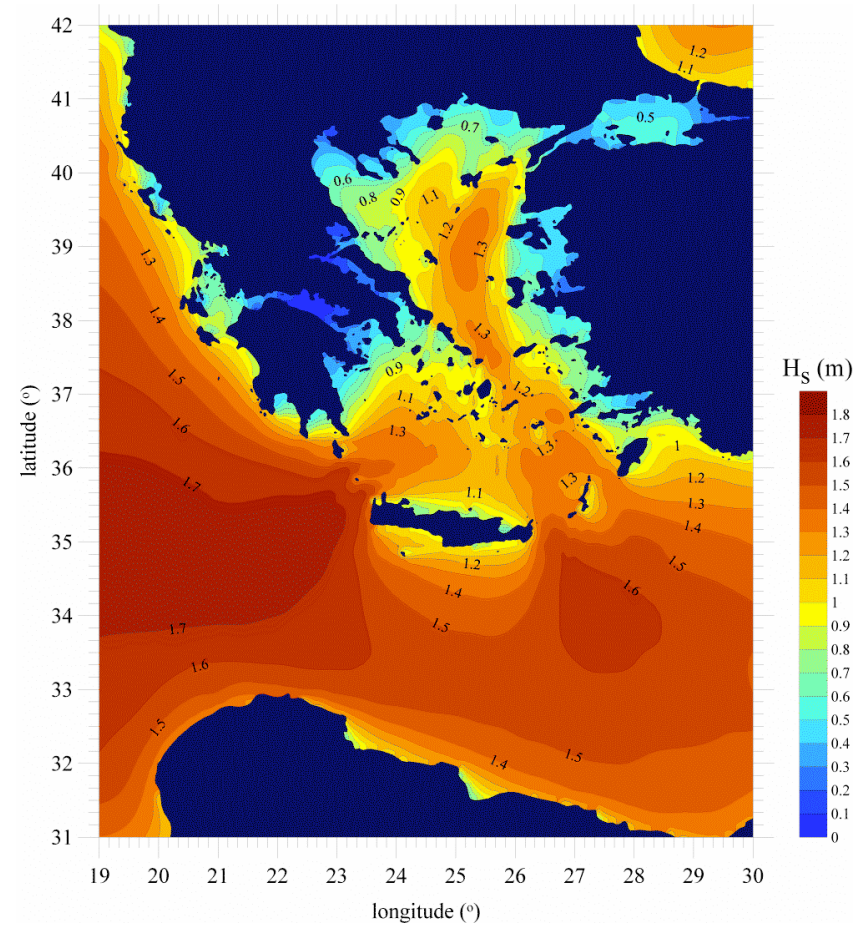

Fig. (8). Spatial distribution of mean significant wave height for winter in the studied area.

In Figs. (10,11), the isopleths $P\left[U_{W}>11 \mathrm{~ms}^{-1}\right]$ and $P\left[H_{S}>2.5 \mathrm{~m}\right]$ for the winter season are respectively pre- sented. The isopleths $P[X>x]$ are the contours of frequency of occurrence (\%) of the random event $X>x$. The results shown in these figures are in accordance with the above mentioned observations: the isopleths $P\left[U_{W}>11 \mathrm{~ms}^{-1}\right]$ and $P\left[H_{S}>2.5 \mathrm{~m}\right]$ corresponding to the highest values of frequency of occurrence appear at the same areas where the highest wind and wave intensities do, as those described in Figs. (6) and (8), respectively.

The spatial distribution of the mean annual wind speed and significant wave height, as well as of the annual wind and wave directionality, exhibited many similarities with the corresponding winter distributions. More detailed commentaries on the aforementioned behaviour will be given in the conclusive section of this work.

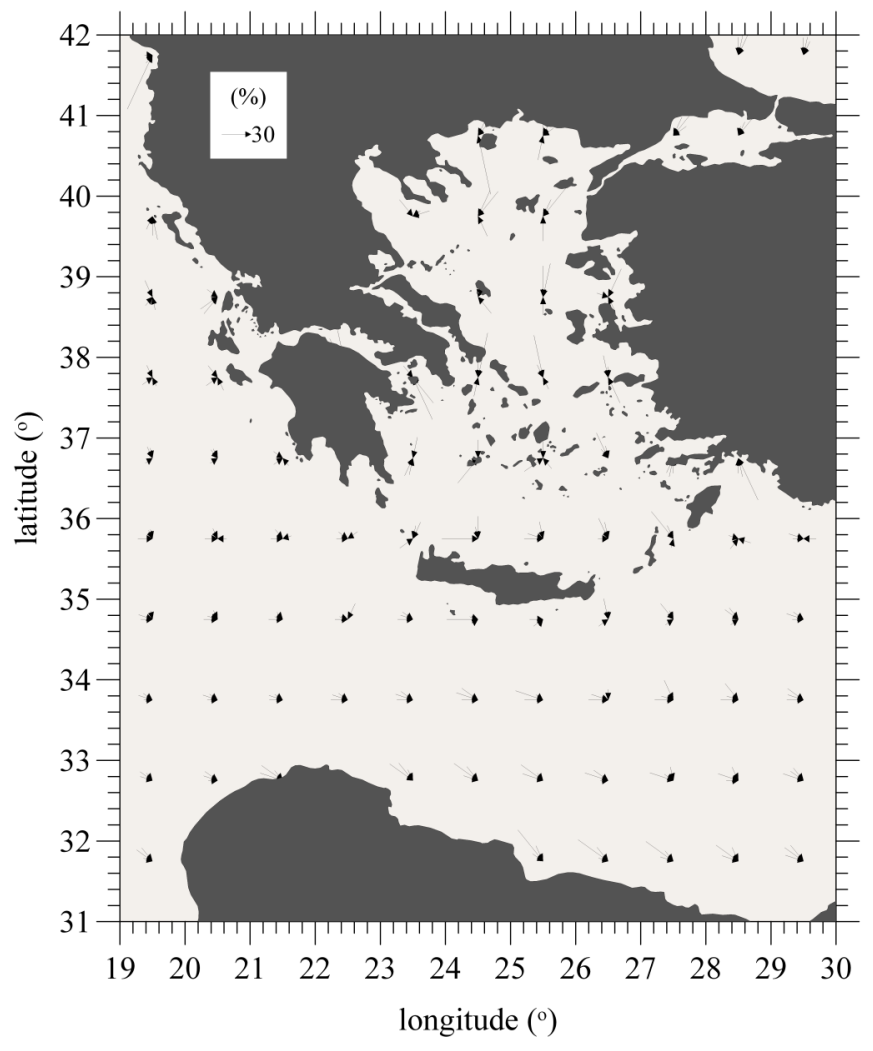

Fig. (9). Spatial distribution of the three most probable wave directions for winter in the studied area.

On a mean annual basis, the most extreme wind and wave conditions were observed at the grid-point with coordinates $\left(27^{\circ} 54^{\prime} \mathrm{E}, 34^{\circ} 15^{\prime} \mathrm{N}\right)$, located around $195 \mathrm{~km}$ southern of Rhodes Isl. In Figs. (12) and (13) the annual histograms of $U_{W}$ and $H_{S}$ are presented for the grid point $\left(27^{\circ} 54^{\prime} \mathrm{E}\right.$, $\left.34^{\circ} 15^{\prime} \mathrm{N}\right)$. In Fig. (13), the log-normal cumulative distribution function is also fitted to the data. For the same point, the sample size $N$, the annual mean value $m$, the standard deviation $s$, the maximum value $\max$ and the coefficient of variation $C V$ for $U_{W}$ and $H_{S}$ are presented in Table 2. The coefficient of variation $C V$ is a dimensionless quantity (defined as the ratio of the standard deviation divided by the mean) measuring the dispersion of the data points around the mean. $C V$ is used when comparing data sets with different 
units, since the standard deviation of the data should always be understood in the context of the corresponding mean. In this connection, the degree of variation of significant wave height is by far greater than the one corresponding to the wind speed, although the corresponding histograms do not reveal this issue; see also Figs. (12) and (13).

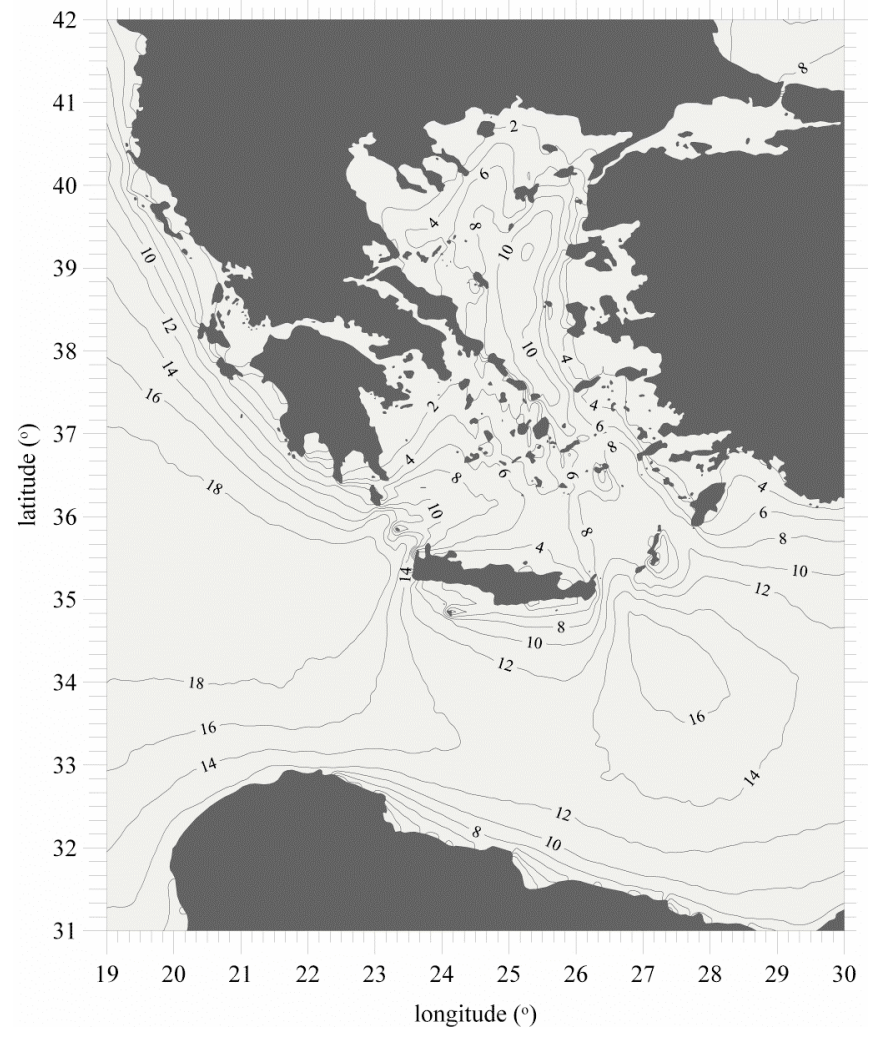

Fig. (10). Isopleths of the random event $U_{W}>11 \mathrm{~ms}^{-1}$ for winter in the studied area.

In Fig. (14), a chart presenting synthetic information on $H_{S}, \theta_{\text {WAVE }}$ and frequency of occurrence is depicted for the same grid point. The coloured bins correspond to wave height intervals; the radius axis corresponds to the frequency of occurrence and the angle axis to the mean wave direction. The corresponding chart for $U_{W}$ is depicted in Fig. (15). In these figures wind and wave directions seem to be in good agreement. In addition, the most intense sea-states are propagating from the sector $\left[255^{\circ}, 330^{\circ}\right]$, i.e., from directions roughly corresponding to the longitudinal axes passing through the straits Rhodes Isl. - Karpathos Isl. and Crete Isl. - Kassos Isl.; see also Axis A (red solid line) and Axis B (red dashed line) in Fig. (16). Wind speed follows the same behaviour.

\section{AN OVERVIEW OF THE WIND AND WAVE CLI- MATE OF THE HELLENIC SEAS}

\section{General}

The Aegean Sea is characterized by relatively short fetch durations and lengths (especially from north to south and from east to west and vice versa) and relatively low swells; thus, the annual wind and wave climate of the area appeared in general considerably mild. Nevertheless, extreme weather and wave phenomena appeared in specific areas, characterized mainly by short durations. Those areas were usually straits, where the wind speed and the wave height are significantly intensified due to the channeling effect. Such an extreme example was the meteorological "bomb", which took place in January 2004 and caused a maximum significant wave height of about $11 \mathrm{~m}$ in the straits between Mykonos Isl. and Ikaria Isl. (see Fig. 16).

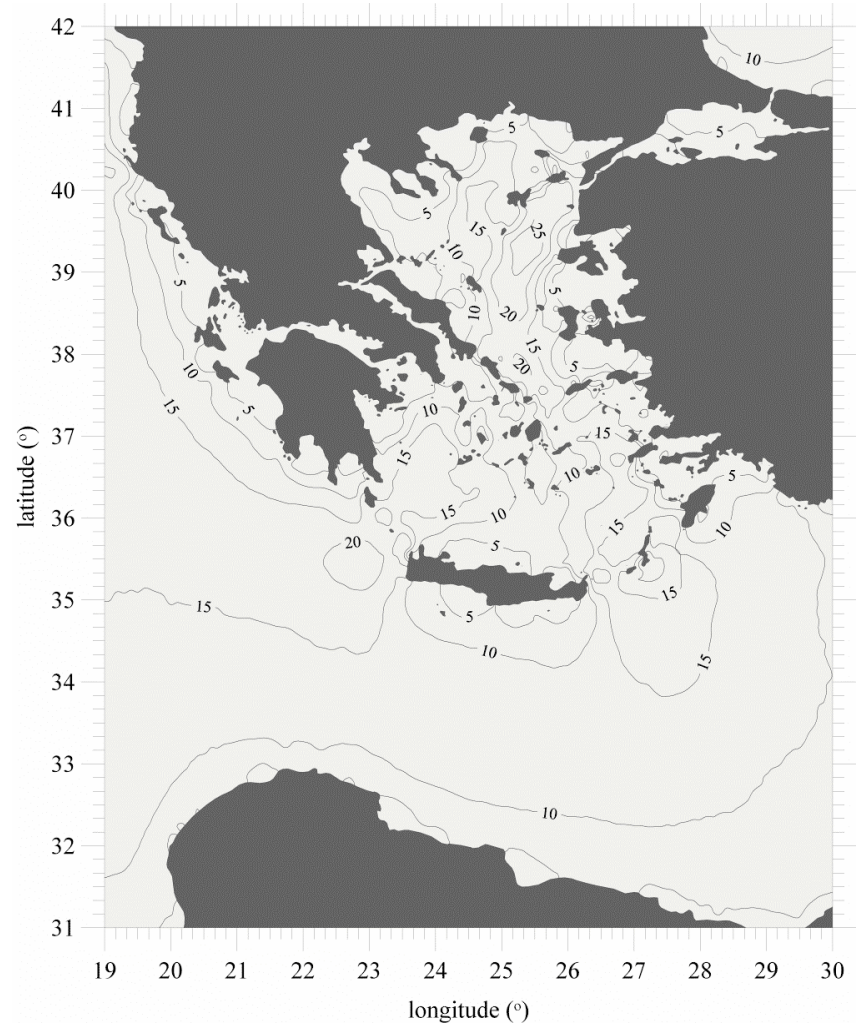

Fig. (11). Isopleths of the random event $H_{S}>2.5 \mathrm{~m}$ for winter in the studied area.

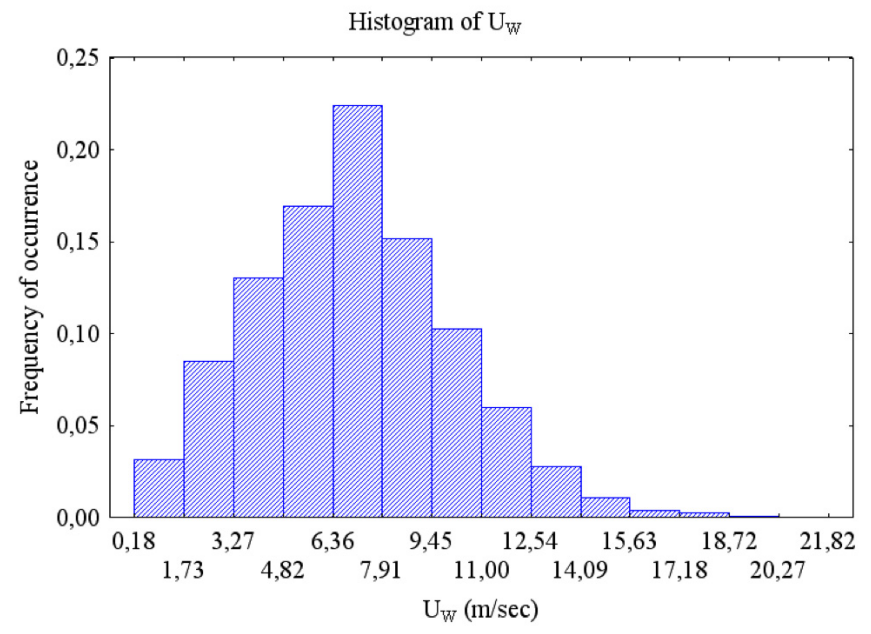

Fig. (12). Annual histogram of wind speed at grid point $27^{\circ} 54^{\prime} \mathrm{E}$, $34^{\circ} 15^{\prime} \mathrm{N}$. 


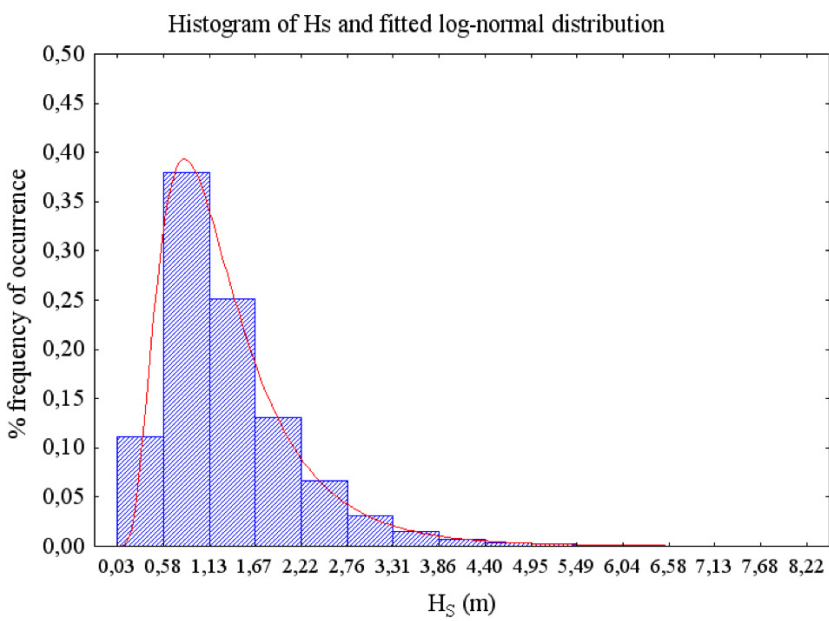

Fig. (13). Annual histogram of significant wave height at grid point $27^{\circ} 54^{\prime} \mathrm{E}, 34^{\circ} 15^{\prime} \mathrm{N}$ along with the fitted log-normal distribution.

Table 2. Annual Statistics of $H_{S}(\mathrm{~m}), U_{W}\left(\mathrm{~ms}^{-1}\right)$ and $T_{P}(\mathrm{~s})$ for Grid Point $27^{\circ} 54^{\prime} \mathrm{E}, 34^{\circ} 15^{\prime} \mathrm{N}$

\begin{tabular}{|c|c|c|c|}
\hline \multirow{2}{*}{ Statistics } & \multicolumn{3}{|c|}{ Parameter } \\
\cline { 2 - 4 } & $\boldsymbol{H}_{\boldsymbol{S}}$ & $\boldsymbol{U}_{\boldsymbol{W}}$ & $\boldsymbol{T}_{\boldsymbol{P}}$ \\
\hline \hline$N$ & 29218 & 29218 & 29215 \\
\hline$m$ & 1.34 & 7.04 & 6.21 \\
\hline$s$ & 0.81 & 3.09 & 1.69 \\
\hline$m a x$ & 8.22 & 21.81 & 16.08 \\
\hline$C V$ & 60.09 & 43.97 & 27.23 \\
\hline
\end{tabular}

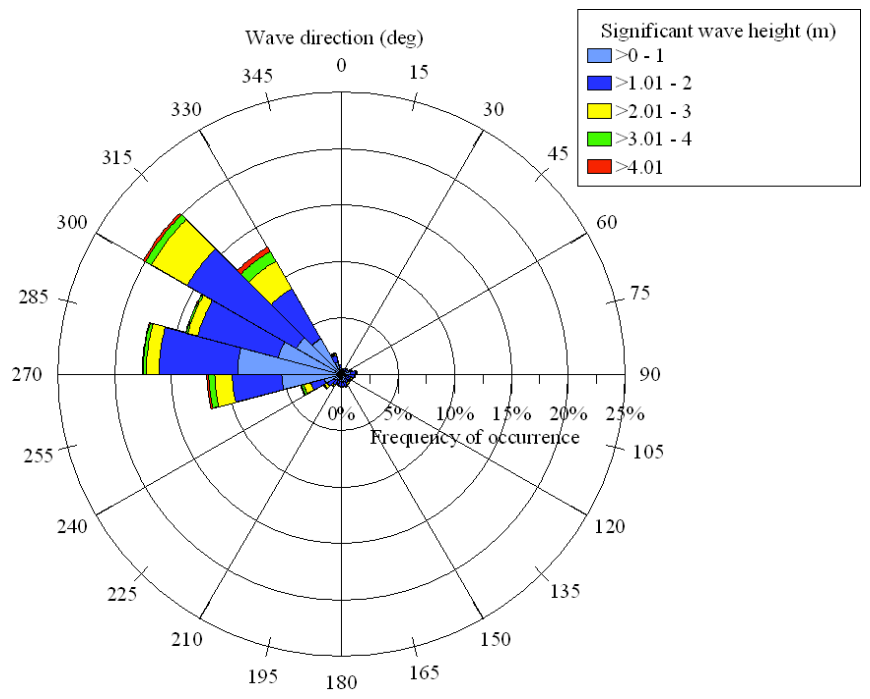

Fig. (14). Annual wave chart presenting synthetic information on $H_{S}, \theta_{\text {WAVE }}$ and frequency of occurrence at grid point $\left(27^{\circ} 54^{\prime} \mathrm{E}\right.$, $\left.34^{\circ} 15^{\prime} \mathrm{N}\right)$

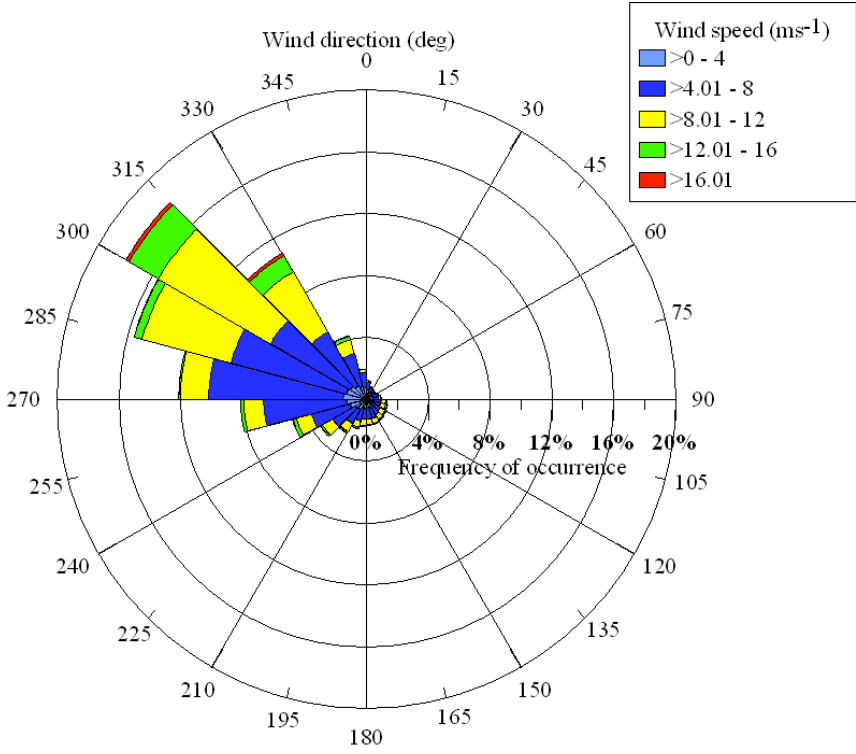

Fig. (15). Annual wind chart presenting synthetic information on $U_{W}, \theta_{W I N D}$ and frequency of occurrence at grid point $\left(27^{\circ} 54^{\prime} \mathrm{E}\right.$, $\left.34^{\circ} 15^{\prime} \mathrm{N}\right)$

The effects of the fetch lengths and the channeling effect were evident, specifically in the straits between Kythira Isl. and Crete Isl., Kassos Isl. and Crete Isl., as well as Karpathos Isl. and Rhodes Isl. Swell waves were also observed at these areas and are characterized by relatively small values of wave height.

In contrast, relatively long fetch lengths characterize the Ionian, the Libyan and the Levantine Seas. In particular, the Ionian Sea is stormier than the Aegean on a mean annual basis, while swell is also a characteristic feature of the entire area. However, the variability of the wind directions combined with the short fetch durations does not favour the development of extreme sea states. The more intense sea states were observed at the straits connecting the Aegean and the Ionian Seas. Another important difference between the two areas was that the eastern coasts of the Ionian Sea were subject to more intense sea states than the coasts of the Aegean Sea. This is due to long fetches and propagation of swell from N-NW and S-SW directions.

\section{Annual Wind and Wave Climate of the Hellenic Seas}

It was clearly observed that the most intense wind and wave conditions appear at three explicitly defined areas of the Hellenic Seas (see Fig. 16):

- Area I: the area N-NE of Cyclades complex, especially the straits between Mykonos Isl. and Ikaria Isl.

- $\quad$ Area II: the area outward the straits between Kythira Isl. and Crete Isl. (SW side), and

- $\quad$ Area III: the areas inside and outward the straits between Kassos Isl.-Crete Isl. and Karpathos Isl.Rhodes Isl. 


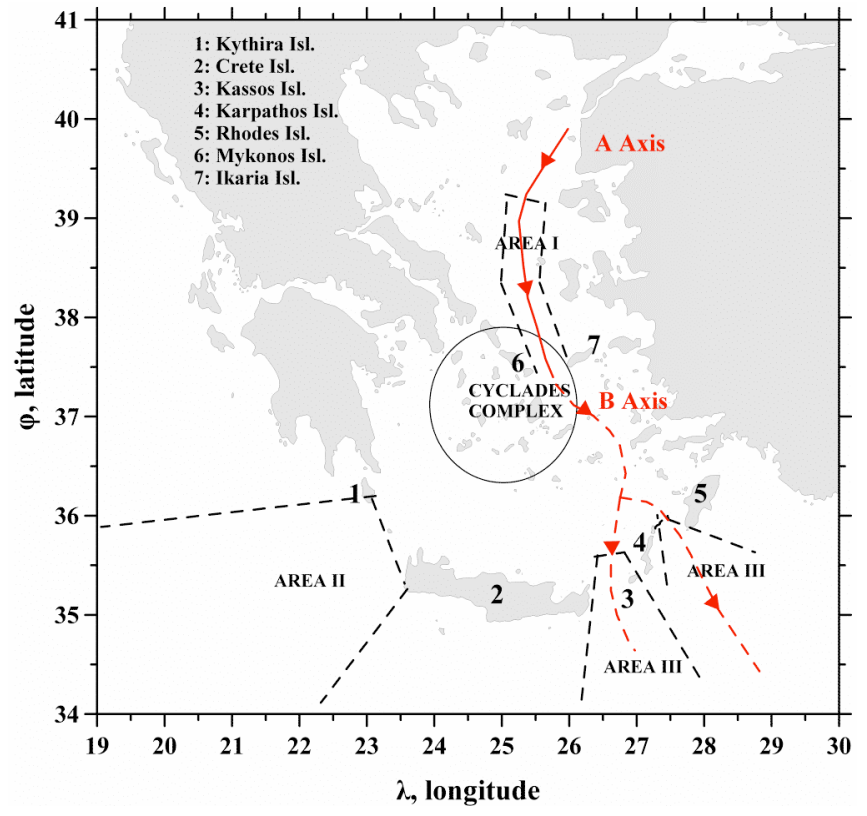

Fig. (16). Main wind and wave propagation patterns of the Hellenic Seas.

A general feature of the wind and wave propagation patterns is that wind and waves propagate from the edge of the Dardanelles Straits to the South Aegean, starting from N-NE directions (at Dardanelles Straits) and ending to NW directions at the south Aegean (see A-axis, red solid line Fig. 16). Wind and wave direction of propagation are generally in good agreement. The weather and wave systems partly relax on the Cyclades complex, resulting to milder - on a mean annual basis - conditions in the enclosed regions. On the other hand, the NE Cyclades, while acting as a breaker to the wind and wave propagation from the northern Aegean Sea, simultaneously drive and amplify, by means of the channelling effect, the corresponding fields, more so in the southeastern areas. Consequently, at specific straits within the Cyclades Complex, wind and wave intensities higher than the prevailing ones at the neighbouring areas were quite frequently observed. Along the southern part of the main propagation A-axis, which is extended in an arc, starting at the straits between Mykonos Isl. and Ikaria Isl. and terminating at the southeast (around $\varphi=37.75^{\circ}, \lambda=26.30^{\circ}$ ), the maximum of wind speed and significant wave height was identified for the entire study area during the 10-year hindcast period. The extreme event took its highest intensity at 22 January 2004, 18:00 UTC, with the following characteristics: $H_{S}=11.0 \mathrm{~m}, T_{p}=13.3 \mathrm{~s}, \theta_{W A V E}=345.4^{\circ}, U_{W}=27.9 \mathrm{~ms}^{-1}$ and $\theta_{W I N D}=339^{\circ}$. The meteorological "bomb" reached a record low-pressure value $(972 \mathrm{hPa})$ over the Aegean Sea and caused considerable damages over many islands; see also Lagouvardos et al. [18].

As far as the Ionian Sea is considered, a simpler situation was observed, since it is an open sea area. The area is characterized by wind and wave propagation patterns from multiple directions. The prevailing weather and wave systems are originating from the east Italian coasts, the Taranta bay and the north Adriatic coasts and head towards the western coasts of Peloponnesus and Ionian Islands. Since the fetches that correspond to the above directions, as well as to the SSW directions, are long, the Ionian is the Hellenic Sea exhibiting the highest wind and wave potential in a mean annual basis. The local maxima were detected offshore the southern coasts of Crete Isl.

\section{Seasonal Wind and Wave Climate of the Hellenic Seas}

The main features of wind and wave propagation and the spatial distribution of the corresponding intensities in the Hellenic Seas appeared to have small differences among seasons, though significant differences occurred as far as the mean intensities of wind speed and wave height are considered.

More specifically, the spatial distribution of the most probable wind and wave directions and of the mean wind speed and wave height followed, for each season, the annual behaviour described in the foregoing section. Within the enclosed sea areas of the Cyclades complex mild conditions observed during all seasons.

The most intense wind and wave conditions occurred during the winter months, when the mean wind speed reached in places values over $8 \mathrm{~ms}^{-1}$, and the mean significant wave height values over $1.7 \mathrm{~m}$. In spring, summer and autumn the prevailing wind and wave conditions were rather mild, though high intensities appeared in certain areas of the Ionian Sea during spring and the Aegean Sea during summer. More specifically, in the Aegean Sea, the summer season is characterized by the "etesian" winds blowing from north to south.

As already mentioned in the foregoing section, there are three areas (Area I, II and III) where the highest wind and wave intensities occurred. Although these areas remain, more or less, the same for all seasons, specific differences were identified as they are presented in Table $\mathbf{3}$.

\section{CONCLUSIONS}

In this work, the wind and wave climate of the Hellenic Seas is being assessed, based on 10-year (1995-2004) hindcast data generated by an improved version of the SKIRONEta atmospheric model and the WAM-cycle 4 wave model, implemented with a high spatial and temporal resolution. The hindcast results were calibrated by means of systematic measured in-situ data from the POSEIDON buoy network.

On a mean annual basis, the overall wind and wave climate appeared considerably mild. Nevertheless, extreme short-duration weather and wave phenomena occurred in specific areas, usually straits, where the wind speed and wave height are both intensified due to the channeling effect. Winds blowing from northern directions (and waves following the same propagation patterns) are clearly the prevailing feature of the Aegean Sea. In the Ionian Sea, the wind and wave propagation patterns were more obscure, since there is lack of a definite and well formed behaviour.

Let us note that the relatively short length of the hindcast time series does not allow definite conclusions concerning long-term climatic and inter-annual variability of the Hellenic Seas, with respect to the corresponding climatic changes of the Mediterranean. This could be achieved in the 
Table 3. Local Maxima of Mean Wind Speed and Significant Wave Height For Areas I, II and III with Respect to Each Season

\begin{tabular}{|c|c|c|c|}
\hline Area & $\boldsymbol{H}_{\mathrm{s}}$ & $U_{\mathbf{w}}$ & Remarks \\
\hline \multicolumn{4}{|r|}{ Winter } \\
\hline I & $1.3 \mathrm{~m}$ & $8 \mathrm{~ms}^{-1}$ & Wide area of local maxima along the A axis (Fig. 16) extending to the central Aegean. \\
\hline II & $1.7 \mathrm{~m}$ & $8 \mathrm{~ms}^{-1}$ & A very large area of permanently intense sea states extending SW of the straits between Kythira Isl.-Crete Isl. \\
\hline III & $1.6 \mathrm{~m}$ & $7 \mathrm{~ms}^{-1}$ & An area extending SE of the straits between Kassos Isl.-Crete Isl. \\
\hline \multicolumn{4}{|r|}{ Spring } \\
\hline I & $1 \mathrm{~m}$ & $7 \mathrm{~ms}^{-1}$ & See the above comments for area I. \\
\hline II & $1.3 \mathrm{~m}$ & $7 \mathrm{~ms}^{-1}$ & A very limited area offshore the W-SW coasts of Crete Isl. \\
\hline III & $1.1 \mathrm{~m}$ & $7 \mathrm{~ms}^{-1}$ & See the above comments for area III. \\
\hline \multicolumn{4}{|r|}{ Summer } \\
\hline I & $1.3 \mathrm{~m}$ & $8 \mathrm{~ms}^{-1}$ & Etesian winds dominate and the area of local maxima is limited to the southern part of the A axis. \\
\hline II & $1.1 \mathrm{~m}$ & $7 \mathrm{~ms}^{-1}$ & A large area extending from the SW coasts of Crete Isl. to the north coasts of Africa \\
\hline III & $1.3 \mathrm{~m}$ & $8 \mathrm{~ms}^{-1}$ & See the above comments for area III. \\
\hline \multicolumn{4}{|r|}{ Autumn } \\
\hline I & $1 \mathrm{~m}$ & $7 \mathrm{~ms}^{-1}$ & Same mean intensities as during spring. Wide area of local maxima along the A axis (Fig. 16) extending to the central Aegean. \\
\hline II & $1.2 \mathrm{~m}$ & $6 \mathrm{~ms}^{-1}$ & A very limited area offshore the W-SW coasts of Crete Isl. \\
\hline III & $1.1 \mathrm{~m}$ & $7 \mathrm{~ms}^{-1}$ & See the above comments for area III. \\
\hline
\end{tabular}

near future by extending the wind and wave simulation period.

Finally, since

(i) the hindcast results presented in this work describe the mean, in the statistical sense, wind and wave state of the Hellenic seas, and

(ii) the hindcast data are only approximations of the real states, any assessment of the wind and wave climate of a specific site should not solely be based on the above results, but also on simulations and/or measurements concerning the particular site.

\section{ACKNOWLEDGEMENTS}

1. This work has been supported by the Hellenic General Secretariat of Research and Technology within the context of the project entitled "An Enhanced operational System for wave monitoring and Prediction with applications in HEllenic Navigation" (ESPEN).

2. The POSEIDON-I project (1997-2000, budget 14.1 MEuro) was funded by the EEA-EFTA Mechanism $(85 \%)$ and the Hellenic State $(15 \%)$. POSEIDON-II project (2005-2008, budget 9.8 MEuro) is funded by the EEA-GRANTS FINANCIAL INSTRUMENT $(75 \%)$ and the Hellenic State $(25 \%)$. The project promoter is the Hellenic Centre for Marine Research.

3. The authors are grateful to all reviewers for their comments and suggestions.

\section{REFERENCES}

[1] G. A. Athanassoulis and E. K. Skarsoulis, Wind and Wave Atlas of the Northeastern Mediterranean Sea. Athens: National Technical University of Athens, Laboratory of Ship and Marine Hydrodynamics, 1992.

[2] The Med-Atlas Group: P. Gaillard, P. Ravazzola, C. H. Kontolios, et al. Wind and Wave Atlas of the Mediterranean Sea. Western European Armaments Organization Research Cell, 2004.

[3] L. Lopatoukhin and A. Boukhanovsky, Ed., Wind and wave climate of the Baltic, North, Black, Azov, Mediterranean Seas, St. Petersburg: Russian Maritime Register of Shipping, 2006 (in Russian).

[4] T. H. Soukissian, M. Hatzinaki, G. Korres, A. Papadopoulos, G. Kallos, and E. Anadranistakis, Wind and Wave Atlas of the Hellenic Seas. Anavyssos: Hellenic Centre for Marine Research, 2007.

[5] T. H. Soukissian, G. T. H. Chronis, and K. Nittis, "POSEIDON Operational Marine Monitoring System for Greek Seas", Sea Technology, vol. 40, pp. 31-37, July 1999.

[6] The Eurowaves Group, "Eurowaves: A User Friendly Tool for the Evaluation of Wave Conditions at any European Coastal Location", Final Technical Report, 2000

[7] F. Mesinger, Z. I. Janjic, S. Nickovic, D. Gavrilov, and D. G. Deaven, "The steep-mountain coordinate: Model description and performance for cases of Alpine lee cyclogenesis and for a case of an Appalachian redevelopment", Monthly Weather Review, vol. 116, pp. 1493-1518, July 1988.

[8] G. Kallos, S. Nickovic, A. Papadopoulos, et al., "The regional weather forecasting system SKIRON: An overview", in Symposium on Regional Weather Prediction on Parallel Computer Environments, 1997, pp. 109-122.

[9] A. Papadopoulos, G. Kallos, P. Katsafados, and S. Nickovic, "The Poseidon weather forecasting system: An overview", The Global Atmosphere and Ocean Systems, vol. 8, pp. 219-237, July 2002.

[10] WAMDIG: The WAM-Development and Implementation Group, S. Hasselmann, K. Hasselmann, E. Bauer et al., "The WAM Model - a third generation ocean wave prediction model", Journal of Physical Oceanography, vol. 18, pp. 1775-1810, December 1988. 
[11] G. J. Komen, L. Cavaleri, M. Donelan, K. Hasselmann, S. Hasselmann, and P. A. E. M. Janssen, Dynamics and modeling of ocean waves. Cambridge: Cambridge University Press, 1994.

[12] T. H. Soukissian, L. Perivoliotis, A. Prospathopoulos, and A. Papadopoulos, "Performance of three numerical wave models on the aegean sea. first results", in 11th International Offshore and Polar Engineering Conference, 2001, vol. III, pp. 40-45.

[13] T. H. Soukissian, and A. Prospathopoulos, "Implementation of the 3rd Generation Wave Model WAM-cycle 4 in Aegean Sea", Technika Chronika (Scientific Journal of the Technical Chamber of Greece), IV, vol. 23, pp. 7-19, January 2003 (in Greek with extended summary in English).

[14] A. Sterl, and S. Caires, "Climatology, Variability and Extrema of Ocean Waves: the Web-based KNMI/ERA-40 wave atlas", International Journal of Climatology, vol. 25, pp. 963-977, June 2005.
[15] T. H. Soukissian, and A. Prospathopoulos, "The errors-in-variables approach for the validation of the WAM wave model in the aegean sea", Mediterranean Marine Science, vol. 7, pp. 47-62, June 2006.

[16] T. H. Soukissian, and C. Kechris, "About applying linear structural method on ocean data: adjustment of satellite wave data", Ocean Engineering, vol. 34, pp. 371-389, March 2007.

[17] X. L. Wang, and V. R. Swail, "Changes of extreme wave heights in Northern Hemisphere oceans and related atmospheric circulation regimes", Journal of Climate, vol. 14, pp. 2204-2221, May 2001.

[18] K. Lagouvardos, V. Kotroni, and E. Defer, "Synoptic environment related to rapid cyclogenesis in the Eastern Mediterranean", $A d$ vances in Geosciences, vol. 7, pp. 115-119, February 2006.

(C) Soukissian et al.; Licensee Bentham Open.

This is an open access article distributed under the terms of the Creative Commons Attribution License (http://creativecommons.org/licenses/by/2.5/), which permits unrestrictive use, distribution, and reproduction in any medium, provided the original work is properly cited. 